\title{
CONFERÉNCIA
}

\section{A CULTURA AMERICANA - RÚSTICA OU URBANA?}

O problema básico do continente sul-americano é, desde 1492, a tensão entre a cultura européia e a cultura autóctone. Uma tendência marcada para a europeização vê-se contrariada pela fôrça misteriosa do solo ibero-americano. Estas fôrças telúricas não se manifestaram em tôdas as épocas e em todos os pontos da vastíssima área com a mesma intensidade, mas nunca, porém, e em parte nenhuma foram tão fracas, tão insignificantes que pudessem ser ignoradas como elementos construtivos da cultura latino-americana. $E^{\prime}$ que a América do Sul representa evidentemente uma síntese, uma das sínteses mais curiosas e de maior potência criadora que se operou no mundo entre autóctones e europeus da qual hoje em todo o caso já sabemos que um dia será tão importante para a humanidade como a penetração do grandioso patrimônio espiritual da antiguidade grega e romana no mundo etrusco, celta e ibérico.

Aquêles que pretendem advogar o caráter preponderantemente autóctone da América dentro do quadro desta síntese, pensam em primeiro lugar na regiões com elevada porcentagem de sangue ameríndio, nas extensas regiões à beira dos pampas, nos "llanos", nos campos ou nas selvas; os outros, que só querem ver na América uma Europa rejuvenescida, terão em mente as suas metrópoles: Rio de Janeiro, São Paulo, Buenos Aires etc. que em 1900 talvez tinham a ambição de se tornarem gêmeas de París e que hoje se aproximam com rapidez surpreendente do aspecto de Nova Iorque.

Onde residem de fato as energias criadoras da América? Será a terra americana ou será a cidade quem dará o seu cunho à fisionomia futura do Continente? Será possível transpor êste dualismo, sem mais sem menos, para o eterno contraste entre a cultura rural e a cultura urbana, que é uma das linhas determinantes da história da Europa, ou prevalecerão na América do Sul condições especiais

Nota: Conferéncia pronunciada na Faculdade de Filosofia, Ciências a Letras da Universidace de São Paulo. 
que não permitam identificar a cultura urbana e a cultura rural do Velho Mundo os fenômenos aparentemente semelhantes no Novo Mundo?

O objetivo desta conferência é apenas estudar alguns aspectos desta síntese.

Veio-me a idéia de empreender tal tarefa quando comecei a desenhar um mapa da área no Novo Mundo habitada por europeus por volta do ano de 1535 , isto é nem mesmo 50 anos depois de Cristóvão Colombo descobrir o arquipélago no Mar Caríbio, nem 20 anos depois de Cortez ter destruído no México o império dos aztecas e no momento em que Pizarro se prepara para fazer o mesmo com o estado dos incas no Perú. Só nos próximos anos receberá relatos do seu capitão Almagro, sôbre as regiões mais meridionais do Chile. $\mathrm{Na}$ costa atlântica, os portuguêses acabam de fundar as capitanias, êste primeiro passo para a penetração efetiva do imenso território. $O$ essencial dêste panorama é que para os europeus no Novo Mundo ainda não existe um conceito exato da América do Norte, como também uma visão da América do Sul bem diferente daquela que hoje é corrente. $O$ que se distingue é uma América Ocidental com cidades e uma América Oriental sem cidades. E' esta realmente a descoberta quase empolgante que fazíamos ao estudar o nosso mapa: num lado há um número imponente da metrópoles e empórios comerciais: México, Puebla, Guadalajara, Acapulco, Panamá, Santa Marta, Cumaná, Cartagena, Quito, Guayaquil, Paita, Trujillo, Lima, Cuzco - no outro lado algumas fortalezas nas praias da costa brasileira e as três fundações primitivas da Bahia, do Rio de Janeiro, de São Vicente e de Buenos Aires. E ainda outro resultado: a parte do Continente voltada para a Europa, a oriental, está vazia, a cultura européia firmou pé onde a América olha para a Ásia, para o Ocidente.

E agora o resultado ainda mais digno de nota: um ou dois séculos antes, um mapa das cidades americanas teria mais ou menos - mesmo aspecto, com a diferença que em vez da designação México, se leria Tenochtitlán, que sôbre os alicerces dos edifícios incaicos em Cuzco não se elevariam ainda os conventos cristãos. Não sabemos ao certo se Lima, Quito ou Bogotá já existiam com o centro da cidade de feição característica, mas sabemos em todo o caso que se encontravam nas suas proximidades aglomerações indigenas de certa importância. Em compensação, na época em que México e Cuzco eram metrópoles ínđias, e já muito antes, brilhavam outros nomes como Chanchán com os seus palácios e templos da qual consta que contava trezentas mil almas, na área das culturas litorâneas do Perú, as cidades maravilhosas do império dos maias, tanto na época antiga, como na média e na nova, as metrópoles dos toltecas, zapotecas e mixtecas, dos totonacas e aztecas, cuja população muitas vêzes não ficava longe dos cem mil, com templos imponentes, academias, como Tetzcuco no reinado de Netzahualcóyotl, institutos 
de educação de militares e sacerdotes, conservatórios e centros de belas-artes, cidades nas quais se observavam as estrêlas como na Babilônia e se representava teatro como em Atenas.

E que significa tudo isto? Significa que a colonização espanhola na América, na sua primeira fase, floresce justamente nos pontos em que coincide com a cultura dos autóctones rica em cidades, da qual hoje se crê que recebeu influências decisivas da Ásia, e que essa mesma colonização espanhola fica estéril e pouco maleável nos pontos em que não topa com uma cultura urbana autóctone. A existência de cidades com verdadeiros centros religiosos, políticos e econômicos, e não só de aglomerações de sêres humanos — foi o fator decisivo, sim, a condição prévia para o progresso do desenvolvimento intelectual e espiritual tanto nas últimas fases antes, como nas primeiras fases evolutivas depois da chegada dos espanhóis.

Os portuguêses foram menos felizes e tiveram de enfrentar grandes desvantagens em comparação ao que se deu com os espanhóis. Quis o destino que a costa oriental fôsse habitada por índios de um tão baixo nível cultural que mal se compreende que pertençam ao mesmo complexo étnico que os índios que construiram a pirâmide de Cholula ou criaram o calendário dos maias. Esta circunstância refletiu-se nìtidamente durante séculos na evolução do Brasil.

Acresce ainda um segundo fato ainda mais curioso e atraente que não se refere à função da cidade, por exemplo no seu contraste com a aldeia, mas à expressão que esta função encontrou um determinado tipo de cidade. Para concretizar: que as cidades que os espanhóis edificaram na América eram surpreendentemente semeIhantes, no seu esquema de base, àquelas que já existiam antes.

$\mathrm{Na}$ cidade colonial espanhola a catedral e o cabildo (o templo e a administração, os elementos locais que na hierarquia espiritual e laica ocuparam os primeiros lugares) estão situados na "plaza", no fulcro do sistema urbano, da mesma maneira como o Teocalli e o palácio do soberano da cidade mexicana ou maia. O símbolo religioso está em ambos casos executado mais rica e mais artisticamente do que o símbolo do poder político. A única diferença é que os espanhóis aplicaram mais severamente o sistema de đisposição em xadrês, do que os construtores das metrópoles indianas como Tenochtitlán. Talvez já terão visto numa história da América um plano desta capital do reino dos aztecas, que fazia parte de uma edição do relatório que Cortez enviou a Carlos Quinto em 1524: uma figura perfeitamente geométrica (e nesta abstração quase transcendental) orientada do centro sacral do sistema de coordenadas e preenchida por muitos quarteirões de casas bastante regulares, que na sua estrutura não seria diferente se os espanhóis a tivessem imaginado espontâneamente.

Do ponto de vista crítico não restam dúvidas que o protótipo da cidade renascentista espanhola e portuguêsa, tanto na metrópole 
como nas colônias, é o "castrum" romano e que estamos em face de uma concepção da cidade nascida na Antiguidade à qual os lusohispânicos dão nova vida, prevalecendo assim no urbanismo as mesmas tendências que dominavam no setor literário e artístico. Como não obstante, o plano urbano do índio e do espanhol, ambos a expressão arquitetônica de uma atitude moral e intelectual, coincidem a tal ponto, somos levados a crer que as razóes desta coincidência devem ser muito mais profundas, que estamos em presença de uma espécie de harmonia pré-estabelecida, que, no fundo, deve residir na cịrcunstância de não estarem tão distanciadas como vulgarmente se pensa, o sentimento mágico da vida que caracterizava os índios e a atitude da Espanha da éra dos descobrimentos perante a outra vida, tão aberta às tendências, aos sentimentos místicos. Se o homem mágico, por um lado, julgava poder influenciar e submeter aos seus sentidos o mundo transcendente por determinados atos e ritos, os conquistadores espanhóis e os reis que os mandavam, não estavam, por outro lado, menos convencidos de que, pelas suas conquistas na América tinham obtido, por assim dizer, candidaturas, talvez até direitos à uma especial graça do Senhor e que se tinham aproximado a tal ponto da realização prática de uma "civitas Dei" universal que já a sentiam nas suas mãos.

Em ambos casos (nos primitivos pagãos e nos europeus da $\mathrm{Re}-$ nascença, medularmente cristãos) a idéia mestra era que, no final de contas, se podia ter a deidade ao seu serviço tornando parte da sua ação nas próprias mãos. $O$ templo a dois passos do palácio não significa sòmente que se deseja ter Deus bem perto, como hóspede, mas também, ao mesmo tempo que se pretendia tê-lo (e não só os seus sacerdotes) um pouco sob vigilância. Quem conhece as relações entre Filipe II de Espanha e o Papa sabe que esta concepção não era de todo absurda para um espanhol do século XVI. Deus e o soberano, formando uma unidade, são o vértice do sistema absolutista; à sua volta só há, pelo menos na teoria, servidores, trabantes e satélites; assim como a "Plaza Mayor" ou "Plaza de Armas" das cidades coloniais espanholas e o centro grandioso da vida urbana atrás da qual só há a grande massa dos quarteirões regulares que, em face da "plaza" não têm a coragem de mostrar uma fisionomia própria.

A América do Norte não possuia, antes do seu descobrimento, cidades com a estrutura e a idéia mestra das grandes metrópoles culturais e políticas da América Central e do Sul. Quando o protestantismo dos "Pilgrim Fathers" colonizou aquela parte do extenso Continente, não encontrou elementos que pudessem opôr o que quer que fôsse à sua atividade ideológica e que êle, consciente ou inconscientemente, pudesse utilizar. Por isso, os anglo-saxões eliminaram na América do Norte o elemento autóctone. degredando-o para as "reservations" e fundaram as suas cidades completamente no espírito do protestantismo real e terreno, enquanto que os espanhóis ten- 
taram pelo menos enveredar pelo outro caminho, adotando como solução a síntese entre os dois mundos.

Esta sintese não se limita evidentemente à fisionomia, à urbanística, à disposição das ruas e à distribuição dos edifícios mais importantes; também abrange e sem dúvida com a mesma intensidade, o fluido espiritual que emanava êste complexo composto pelo homem e pela matéria, inteligentemente ordenado.

$\mathrm{E}^{\prime}$ verdade que, à primeira vista, nos quer parecer que as residências dos vice-reis, como México e Lima, onde uma freira Sóror Juana Inés de la Cruz, continua em congenialidade a poesia do grande Góngora, onde um vice-rei espanhol, o Conde de Esquilache, funda uma academia literária no estilo europeu e onde em 1621, apenas seis anos mais tarde do que na Europa Central, se publicam os primeiros jornais, onde os jesuítas representam os seus dramas escolares e interpretam nas universidades São Tomaz da Aquino, não eram, também no setor intelectual, senão uma cópia de Madrí, de Salamanca e de Valladolid. Mas, olhando de mais perto, verificamos que também vivem no âmbito desta cultura urbana historiadores de vulto, sobretudo sacerdotes e alunos seus que nas suas crônicas procuram pôr em evidência a massa hereditária do Continente; que nas universidades, além do grego e do latim, também se ensina o otomí, o náhuatl, o cacchiquel ou o quechua; que para os filhos dos caciques se abrem colégios quase melhores do que os da burguesia branca. Sim, nesta atmosfera da cidade colonial até se traduzem para a língua dos aztecas Lope de Vega e Calderón, para que se possam representar as suas peças perante os índios, como fêz em 1651 Bernardo de Alba, enquanto que, em sentido inverso, o pároco de Tinta no Alto Perú, Antônio Valdés, compõe de fragmentos índios e na língua dos autóctones, o célebre drama do amor que o chefe de grau inferior Ollantá vota à filha do Inca, Cosi-Coyllur, drama êste que foi representado entre 1770 e 1780 .

Até mesmo o elemento essencial em que se apoia esta cultura colonial urbana do Oeste da América, a classe acadêmica, os chamados "letrados", sente-se inspirada pelo "genius loci" da América. Nascida na metrópole e tendo por raiz o humanismo puro, gerou na América individualidades como Pedro de Peralta Barnuevo, catedrático de matemática, astrônomo, teólogo, engenheiro, cosmógrafo, médico e jurisconsulto em Lima entre 1700 e 1740 , que traduziu a "Rodogune" de Corneille em versos espanhóis tão elegantes como os que escreveu em italiano, latim e até mesmo em quechua e que, năo obstante, não representa figura isolada, mas o protótipo daquela espécie de erudito especulativo tão característica do Barroco, designada pelos espanhóis de polígrafos, a última encarnação đo verdadeiro humanismo, antes da éra da especialização científica que no século XIX.se alcançou tão marcada preponderância. Devia-se equipará-los a um Descartes na França e a um Leibniz na Alemanha, se, na sua aspiração a se afirmarem em todos os domínios, não tives- 
sem os seus limites na visão do mundo e da vida espanhola e católica e se, além disso, não tivessem tido aquêle grãozinho de intelectualidade india, que os situa ao lado dos antigos "amautas", os sacerdotes eruditos do Império dos Incas, dos quais o descendente de Incas, Garcilaso, fala nos sews "Comentarios Reales".

À sombra de uma tal camada conservadora e aristocrática, cujo saber assenta na especulação e na crença numa autoridade e de maneira alguma cita em seu abôno a experiência e o ensaio, desenvolvese a primeira etapa da nova cultura colonial, que tem por esteios as três grandes ordens, os franciscanos, os dominicanos e os jesuítas, justamente daqueles que não se retrairam, como os beneditinos da primeira fase da Idade Média, em conventos afastados do mundo, como Monte Cassino na Itália, Cluny na França ou San Milán de la Cogolla na Espanha, mas que atacavam a vida nos seus fulcros e que, situando-se nestes, a procuravam dominar e orientar. Entre estas ordens os dominicanos são declaradamente urbanos, tendo ao seu lado os agostinhos e os mercedários, em número bastante menor, enquanto que os jesuítas se dedicavam da mesma maneira tanto ao ensino nas cidades como à delicada tarefa de missionários rurais entre os índios. O Brasil é o melhor exemplo do êxito com que levaram a cabo tanto uma como a outra tarefa.

De tôdas as manifestações da cultura espiritual e intelectual que receberam o cunho destas ordens religiosas, as mais expressivas e mais duradouras foram a sua arquitetura e a sua arte aplicada. Foram êles que encarregaram mestres europeus de instruirem artistas e artífices índios nas suas escolas profissionais e que, tentando penetrar com cuidado e carinho na vida íntima dos autóctones, desenvolveram aquêle estilo colonial tão tìpicamente americano caracterizado pela circunstância de se introduzirem subreptìciamente nos motivos das catedrais cristãs e nos palácios nobres do Barroco, o ornamento índio às vêzes encoberto pelo elemento decorativo cristão, outras vezes ocupando o seu lugar. Resultam às vêzes fenômenos de assimilação surpreendentes para os quais chamou recentemente a atenção um historiógrafo da arte alemão que trabalha na Universidade de Genebra, Dr. Fritz Muthmann, num extenso e completíssimo estudo com o título "L'argenterie hispano-americane à l'époque coloniale". O Dr. Muthmann escreve (seja-me permitido citar o trecho em português): "Poder-se-ão descobrir muitas analogias entre estas duas artes (a européia e a índia). Ambas provinham de um mundo fabuloso, fantástico, muito real, não obstante, aos olhos dos homens e dos artistas dos dois continentes. Este entrelaçamento das plantas, dos animais, dos monstros, dos demônios e de cenas religiosas, mitológicas e profanas era, para o europeu da Idade Média e para o índio, a imagem da vida, da natureza, do universo. A arte pré-colombiana, que já degenerava antes da Conquista, foi aniquilada; mas as aptidões artísticas, o senso decorativo e, sobretudo, a velha imagem do mundo tinham-se conservado nos ín- 
dios apesar da nova civilização e da nova religião que os conquistadores thes tinham imposto. Tudo isto animou-se de novo sob a influência da arte decorativa européia. $O$ resultado desta contribuição foi uma arte americana na qual grande número de motivos antigos, tanto europeus como índios, recobraram o seu sentido primitivo, a sua frescura e o seu vigor".

Não significa isto, que no domínio da arte, dentro da área da América do Sul colonial com cultura índia urbana, se operou uma síntese entre tendências ideológicas comparáveis, àquela que se deu no domínio do urbanismo e da urbanização?

Foi, portanto, a missão das grandes metrópoles hispano-americanas do oeste preparar o terreno a esta atitude intelectual e espiritual e tratar đa sua transplantação e propagação. Uma das cidades que melhor e mais fielmente desempenharam esta missão foi Lima, çom os seus vice-reis, que, seguindo o traçado das velhas estradas incaicas, construiram duas grandes vias de comunicação com as suas etapas urbanas: a que leva ao sul do Chile e a que conduz à foz do Rio de La Plata, ambas marcadas por uma série de cidades, com várias ligações e avançando através de vastas áreas povoadas por nômades de cultura primitiva, até a costas quase inexploradas. Não seria suficiente considerar esta cadeia de cidades tìpicamente coloniais, das quais a douta Córdoba, fundada em 1573, formava o primeiro elo argentino, ùnicamente dos pontos de vista militar e econômico. Trilharam estas estradas, fazendo lembrar o famoso caminho de peregrinos que, a partir do século XI levava do convento francês de Cluny, através do lendário vale de Roncesvalles, ao santuário de Santigo de Compostela, no noroeste da Península Ibérica, não só missionários e clérigos mas também investigadores e estudantes, com os seus livros e temas literários, poetas e satíricos, artistas e arquitetos, muito antes de, em 1778 , se organizar o correio continental que as integraram oficialmente no sistema econômico e na grande rêde de comunicações do Continente.

Um dos mais curiosos produtos literários da América do Sul, nascido, por assim dizer, à margem de uma destas estradas e que dela recebeu a sua essência espiritual é o célebre "Lazarillo de ciegos caminantes", uma espécie de Baedecker para a estrada de Buenos Aires a Lima, publicada em 1773 nesta cidade por um autor que se designava bombàsticamente de descendente dos incas. Este roteiro reune conselhos práticos aos viajantes com os mais interessantes dados culturais, sociológicos e folclorísticos, sendo um dos poucos livros da época que se podem ler ainda hoje com grande prazer. Já o fato de o autor realçar orgulhosamente a sua ascendência incaica é significativo, mais significativo ainda por o fazer com uma fórmula literária típica da novela picaresca espanhola e num estilo que permite divisar os seus bons conhecimentos da literátura espanho1a. Estamos diante de um exemplo frisante de como por volta do fim 
da éra colonial já se assimilaram mùtuamente na literatura sul-americana elementos autóctones e elementos espanhóis.

Seria fácil indicar exemplos semelhantes de uma profunda in. terpenetração no domínio da arquitetura e em tôda a fisionomia das cidades coloniais espanholas na América. Um dos mais típicos seria sem dúvida Cuzco, a capital arqueológica do Novo Mundo e ao mesmo tempo o grande museu ao ar livre, tanto da América espanhola como da América dos índios. Vasada no fundo de um vale circundado por montes gigantescos, como sede e capital de um império teocrático, ascendera, ultrapassando a sua importância administrativa e militar, à categoria de cidade santa cujo ambiente era determinado pelas manifestações litúrgicas. Quando, em 15 de novembro de 1533, os conquistadores fizeram dela uma cidade espanhola o seu ato mais característico e mais significativo da conquista efetiva foi que substituiram simplesmente o Culto do Sol pelo Culto da Cruz. Acentuaram ainda mais o caráter sagrado da opulenta cidade os clérigos que acompanhavam os conquistadores. Alucinados pela grandeza da sua missão cristã, e animados pelo mais ardente zêlo de exterminar a heresia que se lhes patenteava nos templos majesto. sos, nos palácios imperiais, nos santuários, nos jardins e nos conventos das virgens do sol e até mesmo na imponente fortaleza de Sacsahuaman, edificaram, como já a princípio indiquei, igrejas cristãs sôbre os escombros dos templos incaicos, como símbolo de que Jesús Cristo viera ocupar efetivamente o lugar de Huiracochas, levantaram a sua catedral sôbre os alicerces do templo do herói peruano e edificaram o convento de São Domingos sôbre os fundamentos do Templo do Sol.

Mas na medida em que os espanhóis penetravam nos segredos das velhas tradições, dos mitos e das lendas dos índios, verificaram ser impossivel suprimir simplesmente uma religiosidade tão forte como a sua própria, destruindo templos e santuários. Era necessário conquistar a grande massa dos indígenas não só pelo zêlo da catequese, mas também pela mesma pompa e grandiosidade, até mesmo por ritos semelhantes e símbolos correspondentes àquêles que 1hes eram queridos. Permitiram-se, por isso, nas igrejas cristãs de Cuzco formas ornamentais de origem india e organizaram-se procissões que lembravam os antigos ritos. Conseguiu-se desta maneira que milhares de índios seguissem as imagens cristãs adorando-as com o mesmo fervor que ainda pouco antes votavam aos seus ídolos.

A síntese entre o velho e o novo, ou melhor, entre a cultura autóctone e a cultura importada é, portanto, a característica essencial do espírito das cidades do ocidente americano na éra colonial. Chega-se a compreender efetivamente o que esta síntese significa no momento em que se confronta com ela a fisionomia completamente diferente das cidades atlânticas que só no século XIX chegaram à maioridade. 
Se a estrada de Lima para o Rio de La Plata de que falei não tivesse estabelecido a ligação com o pôrto atlântico de Buenos Aires no fim do século XVIII mas 150 ou 200 anos antes, em vez de, pelo menos no que diz respeito ao domínio intelectual e espiritual, parar diante das portas de Córdoba, todo o pêso do espírito tradicional e crente na autoridade, que predominava nas cidades peruanas teria sido transferido também para Buenos Aires e Montevidéu. A escolástica e a mística teriam lançado raízes nestas duas cidades da mesma maneira como em Lima e em Quito. E' esta, com certeza, uma das origens daquela grande aspiração da segunda metade da éra colonial que se tornou realidade só em 1776, a fundação do vice-reinado de Buenos Aires. Significa ela, do ponto de vista intelectual e espiritual, a tentativa da mãe-pátria com o seu despotismo ilustrado do Século das Luzes, de dar independência política e espiritual em grau relativamente elevado a uma parte do império colonial livre da hipoteca escolástica para assim abrir uma válvula de escape à pressão cada vez maior do racionalismo, antes que fôsse tarde. Mas, de fato, já era tarde. Foi impossível deter a revolução apesar das medidas dos vice-reis no Rio da Prata, rebentando ela no dia 25 de maio de 1810 em Buenos Aires, e três semanas mais tarde em Caracas onde as circunstâncias eram bastante $s \_-$ melhantes.

Na vasta área atlântica do Continente sul-americano - devo lembrar agora o mapa que nos propusemos desenhar - nos vastos territórios povoados por indios primitivos, por caraibas continentais, pelos tupis e guaranis, pelos povos de caçadores e de nômades da selva, pelos índios dos pampas, sem cidades, sem organizações estaduais potentes, sem arquitetura monumental, sem alfabeto e sem substituintes, tinham-se desenvolvido, entretantc, as condiçōes prévias para a formação de cidades completamente diferentes, cidades nascidas de um pequeno pôrto, de uma fortificação levantada contra os índios e que mesmo hoje em dia costumam dever a sua existência à decisão de um prospector de minas, de um engenheiro de caminhos de ferro, de uma emprêsa de colonização ou de especuladores ou que, como a cidade argentina La Plata, em 1882, são delineadas com régua e compasso em obediência a considerações de ordem política ou administrativa. São as cidades do utilitarismo e do positivismo, centros ideais do desenvolvimento da demccracia americana, cidades cuja população aumentou vertiginosamente nas últimas décadas, sobretudo em relação às cidades barrocas do oeste que continuam a viver num período de estagnação. Buenos Aires, Rio de Janeiro e São Paulo entraram e foram além da casa dos dois ou três milhões enquanto que a população de Lima diminuiu entre 1810 e 1942 de 78.000 para 52.000 .

Esta formidável concentração populacional dotou as novas metrópoles atlânticas de uma fôrça de atração mágica que as cidades antigas ocidentais não conheceram. Enquanto que as cidades colo- 
niais típicas da costa do Pacífico, Lima, La Paz, Quito ou Bogotá abrangiram no máximo 2 a $4 \%$ dos habitantes do país, hoje vivem em Buenos Aires mais de $30 \%$ de todos os argentinos e em Montevidéu mais de $28 \%$ de todos os uruguaios. No Brasil observa-se uma concentração semelhante no estado de São Paulo e na cidade do Rio de Janeiro, considerando esta do ponto de vista geográfico e incluindo, portanto, o Distrito Federal. Insistir aqui em evidenciar a formaçâo e a evolução do Brasil que seguiram rumos bem diferentes daqueles que se observam na maior parte da América do Sul de língua espanhola seria "levar cocos para a Bahia" e relatar o que vim ver, aprender e estudar:

Formaram-se, como dizia, na parte atlântica formidáveis reservatórios de captação que não só atrairam e continuam a atrair a população rural mas também os imigrantes europeus e de outras procedências que não foram sòmente, nem são, comerciantes e colonos exclusivamente, mas também literatos, professôres e investigadores das últimas três ou quatro gerações. Enquanto que as cidades coloniais do lado do Pacífico tinham separado severamente a função econômica da fundação intelectual da cidade, manifestando-se o conhecido dualismo Valparaiso-Santiago, Callao-Lima, GuayaquilQuito, Barranquilla-Bogotá, atribuindo a cada uma delas as funções para as quais estavam predestinadas por razóes geográficas, desenvolvem-se os centros que reunem ambas funções: Rio de Janeiro e Buenos Aires são grandes portos, e, ao mesmo tempo, capitais; o seu oceano é o Atlântico, o grande mar euro-americano do século XIX e não o Pacífico dos séculos XVII e XVIII, ùnicamente acessivel pelos transportes terrestres através do Istmo do Panamá.

Puderam então afluir franceses e inglêses, alemães, suiços e austríacos, italianos e eslavos aos quais a economia monopolista do regime colonial havia fechado as portas. Não trazem sòmente homens e capitais, mas na sua bagagem intelectual vêm novas idéias, novas modalidades de pensamento, novos ideais. Os franceses trazem a filosofia positiva, a elegância estética e a tendência para a centralização, fatôres que desde então gravaram traços indeléveis na administração, na vida da sociedade, na filosofia e na literatura da cidade latino-americana; os inglêses contribuem com o "common sense", o senso prático resultando desta influência em que, em vez da literatura das disputas escolásticas e da meditação religiosa as estatísticas, os pareceres e os relatórios absorvem grande parte da tinta de impressão que se gastam nas cidades; os alemães trazem o seu espírito de iniciativa em todos os domínios, a sua capacidade de trabalho e a sua investigação científica. E', evidentemente, impossível enumerar tôdas as contribuições como é óbvio que a contribuição espanhola e a contribuição portuguêsa são correntes ininterruptas.

Se na América colonial do Pacífico o portador da vida intelectual e espiritual era o professor universitário com educação clás- 
sica, que se opunha a ser equiparado ao cidadão normal, que era na maioria dos casos eclesiástico ou jurisconsulto com um ou mais cargos oficiais, no tipo da cidade atlântica, mais jovem, o "burguês" da classe média era o fator de maior importância. $O$ efeito destas elites tão diferentes sôbre a função intelectual e moral das cidades é evidente. Cientes de que delas depende o progresso ou, como êles dizem, a "civilização" do seu país, vêem a sua missão, em primeiro lugar, em promover a educação geral e a instrução de tồdas as classes da população. Sarmiento, já muito cêdo o inteligente adversário ideológico da ditadura argentina por volta de 1840 , realiza 30 anos mais tarde o seu ideal de ser ao mesmo tempo presidente da Nação e educador de nomeada. E' dêle e dos intelectuais da sua têmpera que parte o impulso de reestruturação das 18 repúblicas irmãs, aparecendo aquêle tipo de intelectual conhecido em todo o Continente que se dedica com verdadeira alegria de pioneiro a tão importante domínio como o romance, desprezado, proibido e banido na éra colonial, que fundam jornais de um volume raras vêzes atingido na Europa, de nível elevado e de extraordinária variedade cujas funções compreendem as que competiriam a uma produção livreira ainda embrionária mas que, no decorrer de poucas gerações atinge tão elevado grau que hoje irradia dos seus centros Rio de Janeiro, São Paulo, Buenos Aires - para falar só dos mais importantes até aos recantos dos países vizinhos. A concepção unificadora do americanismo de cunho ibérico encontrou os seus mais enérgicos representantes nestas elites, nesta atitude intelectual das cidades, primeiro na literatura mas, há cerca de três decénios também na tendência de edificar uma casa própria para a filosofia cultural do Continente.

A base đe tôdas estas ideologias é - evidentemente com consideráveis diferençàs de dosagem nas repúblicas ibero-americanas a síntese de indianismo e iberismo, uma síntese, que assenta, aliás, numa base muito mais ampla do que a que existia no período colonial. Resulta esta base mais ampla do fato de se terem agregado aos dois elementos básicos, o índio e o ibérico, ou luso-hispânico, dois outros que os séculos XVII e XVIII não podiam conhecer por se terem fechado os territórios coloniais a tôdas as influências que não proviessem das mães-pátrias: a ingerência geral européia e, num período mais recente, a influência norte-americana que não đeu sòmente a Buenos Aires, ao Rio de Janeiro e a São Paulo a silhueta dos arranha-céus, mas que lhes trouxe também o evangelho da Wallstreet, a cultura cinematográfica de Hollywood, a vida de sociedade de Miami e o ritmo de trabalho de Henry Ford.

Vistas na sua totalidade, estas influências são, no entanto, apenas algumas novas pinceladas num quadro antigo. A essência do problema continua a ser a mesma, quer escrevamos 1550 ou 1950. Hoje como então é um fato que o Mundo Ocidental e o Mundo Autóctone se enfrentam na América Latina e que é a missão do Con- 
tinente Sul-americano enfeixar as energias irradiadas por êstes dois mundos concentrando-as num foco, de realizar a síntese do sentimento da vida essencialmente mágico dos índios com a causalidade dos europeus, a dependência cósmica do homem, da qual uns estão convencidos, com o individualismo que se tornou a diretriz da existência dos outros.

Desde os dias da sua fundação, as cidades latino-americanas intervieram na solução desta tarefa; sim, poder-se-á até mesmo dizer que foi realizada na sua parte essencial pelas camadas educadas das cidades, fôssem elas eclesiásticas ou leigas. Estas camadas educadas estiveram durante séculos dentro do âmbito de uma concepção da História que continuou a orientar-se pelos altos princípios e pelos fatos basilares do Cristianismo, a criação, o pecado original, a redenção e o juízo final, quando noutra parte já se havia humanizado Nosso Senhor declarando que era um técnico muito inteligente e espirituoso ou o filósofo de maior relêvo. As elites intelectuais das cidades hispano-americanas tiveram tempo, tiveram mais de 300 anos para deixar a mística desta concepção agir sôbre os índios que a ela eram tão extremamente sensíveis, conduzindo-os assim a pouco e pouco e quase sem que dessem por isso, para o campo cristão e, portanto, ocidental. As cidades norte-americanas só chegaram ao poder quando no Mundo Ocidental se havia entronizado, ao que parecia, no lugar do compromisso medieval e escolástico entre a fé e a razão, ùnicamente a razão, aquela razão que sabia dizer tão pouco aos corações dos índios do transcendente que domina nos seus mitos e nas suas lendas. A Fé Cristã dos espanhóis e portuguêses soube, por seu lado, demonstrar da maneira mais flagrante as relações entre o indivíduo e o Universo que aztecas e maias, chibchas e aimarás, aruacos e araucanos conheciam das suas lendas da criação, do dilúvio, do pecado e da redenção da Humanidade.

Nesta base as almas luso-hispânicas e a alma índia já se tinham encontrado quando, com a emancipação política, começou a soprar na América do Sul o vento do racionalismo. Milhares e milhares de índios tinham aceito a concepção da vida e do mundo dos conquistadores em vez de serem lançados na indiferença e no ressentimento. Foi assim que a Espanha e Portugal puderam lançar as bases de 20 estados que não só deram provas da sua capacidade vital quando chegou o momento da sua independência política, mas que nessa hora já tinham uma cultura própria, fortemente arraigada no próprio solo.

O fato de ter podido realizar êste grande feito no domínio da cultura sem copiar esquemàticamente a fisionomia das mães-pátrias, é mérito que compete tão essencialmente às cidades, à população urbana da América do Sul que será escusado sublinhá-lo mais uma vez. Este feito levou a que no Continente Sul-americano o conceito de "povo, como unidade étnica, no sentido europeu, é relegado 
para o segundo plano pela tradição histórica e pelà tarefa, considerada quase missão sagrada de abrir ao homem e de pôr ao seu serviço esta terra, esta imensa, promissora e tão bela terra. E' esta uma missão verdadeiramente humanística. $O$ humanismo dos séculos. XVI e XVII mostrou-se à sua altura graças à soberana capacidade de adaptação dos seus intelectuais de cunho declaradamente urbano. Não tenho a mínima dúvida em que o humanismo do século $\mathrm{XX}$ saberá cumprir da mesma maneira, tão alta, tão bela e tão nobre missão.

\section{RUDOLF GROSSMANN}

Professor de Cultura Hispânica e Diretor do Instituto Ibero-Americano da Universidade de Hamburgo. 